\title{
Nondestructive Determination of Stresses in Steel Components by Eddy Current Method
}

\author{
Valentyn Uchanin $1,{ }^{*}$ - Sergej Minakov ${ }^{2}$ - Giuseppe Nardoni ${ }^{3}$ - Orest Ostash 1 - Sergej Fomichov ${ }^{2}$ \\ 1Karpenko Phisico-Mechanical Institute of National Academy of Sciences, Ukraine \\ ${ }^{2}$ Kyiv Politechnical Institute, Ukraine \\ 3I\&T Nardoni Institute, Italy
}

\begin{abstract}
Nondestructive eddy current (EC) method for evaluation of stresses in ferromagnetic steel components based on the stress-induced magnetic anisotropy (MA) changes was investigated. The proposed method is based on the rearrangement of the magnetic domains under stresses due to the reverse magnetostrictive effect (Villari effect). For evaluation of stresses special EC probe was developed. Investigations were carried out with the application of the conventional testing machine for tensile loading and the specially developed experimental set-up for four-point loading for creation the adjusted tensile and compressive stresses on different sided of the loaded specimen. From results obtained some specific properties were determined: the magnetic-mechanical hysteresis existence and the invariance feature in relation to the structural state of the material. The last result can create the outlook for stress measurement independently of the structural state of material as opposed to other known magnetic methods based on coercivity or Barkhausen noise measurements. Two original practical applications of the MA technique for stress determination were realized: the evaluation of the welding-induced residual stresses and the estimation of stresses in the steel bridge framework during the launching to the pillars.
\end{abstract}

Keywords: eddy current, magnetic anisotropy, applied and residual stresses, tensile, compressive, magnetic-mechanical hysteresis, welding, bridge framework

Highlights

- Eddy current method for determination of stresses in ferromagnetic steel components based on MA changes under the stress influence.

- Experimental results concerned with peculiarities of the EC probe signal changes under the tensile and compressive stress influence.

- $\quad$ Results obtained show the magnetic-mechanical hysteresis existence and the invariance feature of the investigated method in relation to the structural state of the material.

- Results of new practical applications, such as: the evaluation of the welding-induced residual stresses and the estimation of stresses in the steel bridge framework during the launching to the pillars.

\section{INTRODUCTION}

Applied and residual stresses can influence the operable state of the structures and components. Especially it is important for welding, because shrinkage, quenching and phase transformations during the welding process create different distributions of residual stresses. Welding-induced tensile residual stresses provoke the brittle fracture and stress-corrosion cracking, which significantly reduce the fatigue life of welded structures in service [1] and [2].

Different destructive and nondestructive methods have been developed to estimate the stress state of the material in different applications [1] to [3].

The nondestructive techniques based on the magnetic phenomena concerned with Barkhausen noise or hysteresis loop parameters evaluation has been applied for determination of the stresses in the ferromagnetic steel components [4] to [9]. These methods provide the possibility of non-contact, reliable and fast inspection with high repeatability of the results obtained. Methods based on Barkhausen noise technique were successfully applied for evaluation the residual stress state in steel weldment [4] to [7]. The effectiveness of Barkhausen noise method for stress measurement was validated by comparative investigations [7] and [8]. The original method based on the combined application of Barkhausen noise and coercive field strength techniques possible to separate the information about structural and stress state of material was proposed in [9]. These methods can be characterized by comparatively low operational frequencies (can be considered as constant) of applied magnetic fields.

The methods based on magnetic elastic (including the magnetic anisotropy (MA)) probes and alternating electromagnetic field application also can be applied for stress determination in the surface layers of the steel components [10] to [21]. In this case, the depth of evaluated material is strongly limited by skin-effect influence due to higher operational 
frequency application. The depth of penetration of electromagnetic field can be changed by the choice of the operational frequency.

In majority publications, the different types of the four-pole probes were applied as primary sensors in MA stress measurement techniques [11] to [19]. The four-pole probe with cross-shaped indivisible core and two excitation and two sensing coils installed on opposite poles (legs) of the core is considered to be one of the most useful among the MA probes [11] and [12]. Other type of the four-pole probe with cross-shaped indivisible core was analyzed in [13]. On each pole (leg) of this probe one excitation coil and one sensing coil are installed. Therefore, this probe consists of 4 excitation and 4 sensing coils. In a many publications the probes for MA based stress measurement were composed of the two coils mounted on the two separated U-shaped (or yoke type) cores, which are positioned mutually-perpendicular each other [14] to [19]. One coil (excitation coil) commonly is connected with the harmonic generator output. And other coil is a sensing coil. Such type probes are interacted with inspected surface by 4 poles situated in the corners of a regular tetragon.

Presented methods are based on the magnetic permeability changes in the ferromagnetic material due to the rearrangements of the magnetic domains under the stresses concerned with the reverse magnetostrictive effect (Villari effect). Furthermore, the tensile and compressive stresses have an influence on the magnetic domains alignment in a different way as presented schematically in Fig. 1. For ferromagnetic material under stress, the elliptical diagram for angular distribution of directional permeability was assumed [17] and [18]. a)

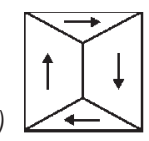

b)

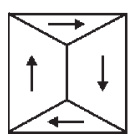

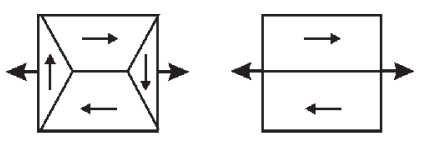

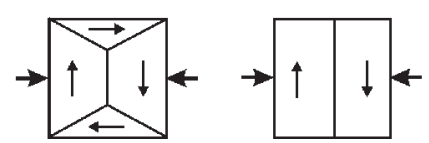

Fig. 1. Rearrangements of magnetic domains under the influence of a) tensile and b) compressive loadings

Due to high enough operational frequencies the MA methods can be considered as one of the versions of the EC method. For such approach, the big experience of EC method development can create other fruitful consideration. In this paper, the investigations of EC method with new type of stress sensitive EC probe are presented. The signals of developed EC probe under the stresses were investigated with conventional EC flaw detector to underline the EC nature of investigated MA method. Some new results of the practical applications, such as the determination of residual stress distribution near the circumference pipeline welding and the estimation of stresses in the bridge framework walls during the launching procedure, also are presented.

\section{EDDY CURRENT PROBE, INSTRUMENTATION, SPECIMENS AND INVESTIGATION PROCEDURES}

Our comparative investigations show that better performance for stress induced MA changes detection can be achieved by double differential type probe [20] and [21]. This type of probes is composed of two identical excitation coils 1 and two identical sensing coils 2, which are situated in the tetragon corners, as it is shown on Fig. 2. For presented investigation stress sensitive double differential MDF 1801 type EC probe with $18 \mathrm{~mm}$ operational diameter was produced. In this probe, all coils are installed on 4.3 $\mathrm{mm}$ diameter ferrite cores [20]. Excitation coils 1 of this probe are connected in series each other and oriented in order to create the identical and opposite primary electromagnetic fields as it is shown in Fig. 3. Due such design double differential type EC probes have some remarkable peculiar properties in the distribution of primary electromagnetic field and eddy currents, such as the existence of the characteristic neutral plane, in which the vertical component of summarized primary electromagnetic field is equal to zero. Due such peculiarity the high sensitivity is obtained in combination with high level of lift-off suppression [20].

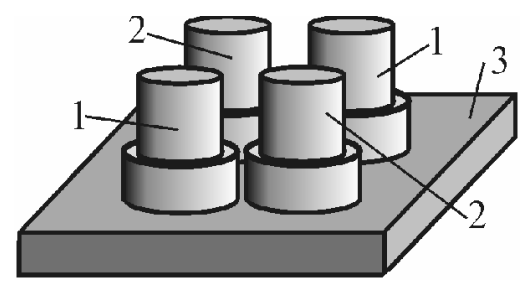

Fig. 2. MA sensitive double differential type EC probe: 1 - ferrite cores with excitation coils,

2 - ferrite cores with sensing coils, 3 - inspected object

Sensing coils 2 are oriented to be sensitive to the vertical component of the electromagnetic field and are installed in neutral plane, where this component for isotropic media is equal to zero. Due to the opposite connection of sensing coils 2 (Fig. 2) the double differential type of signal response is realized. 


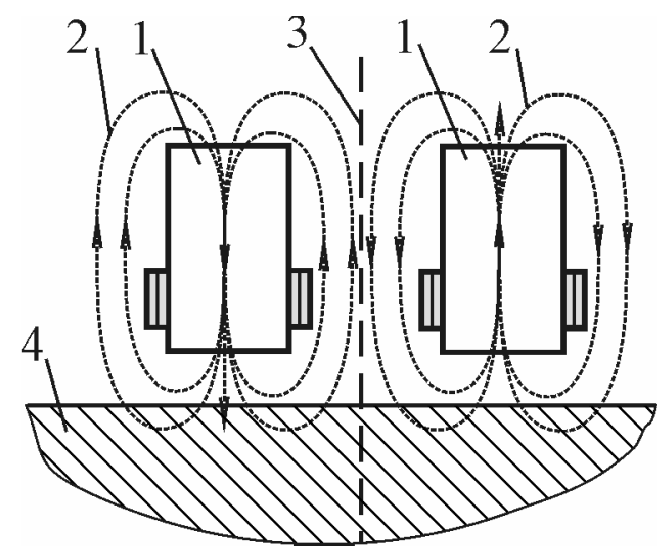

Fig. 3. The distribution of primary electromagnetic field and eddy currents in the double differential type EC probes:

1 - ferrite cores with excitation coils, 2 - primary field, 3 - neutral plane, 4 - inspected object

Conventional Eddycon VD3.81 type EC flaw detector (Fig. 4) was applied for observation of the EC probe signal response changes during the loading [21].

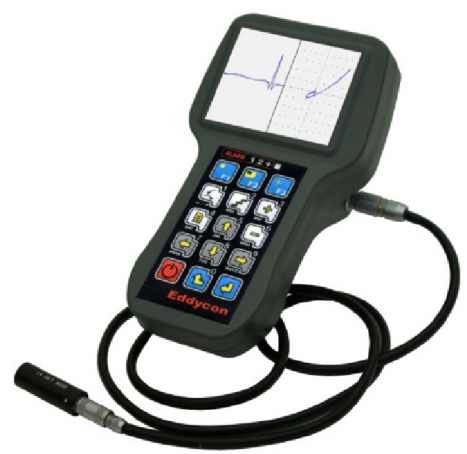

Fig. 4. EC flaw detector Eddycon VD3-81

Structural scheme of Eddycon VD3-81 flaw detector (Fig. 5) consists of: EC probe 1; excitation generator 2; input multiplexer 3; preamplifier 4; vector signal summarizer 5 ; balancing generator 6 ; amplifier 7; ADC 8; programmed logic integrated chip 9; processor 10; display 11; USB controller 12; audio controller 13; keyboard 14; sound alarm generator 15; alarm LED 16.

Eddycon VD 3-81 flaw detector permits to represent the EC probe signal responses in complex plane on the operational frequencies from $50.0 \mathrm{~Hz}$ to $12.0 \mathrm{MHz}$. The balancing generator 6 produce the balancing sinusoidal signal for vector summarizer 5 under the control of the programmed logic integrated chip 9. The amplitude and phase of this balancing signal was choosing to set zero signal response for probe situated on the unloaded specimen. For our investigation it is very useful the possibility to monitor the hodographs of signal response in complex plane during the specimen loading and unloading.

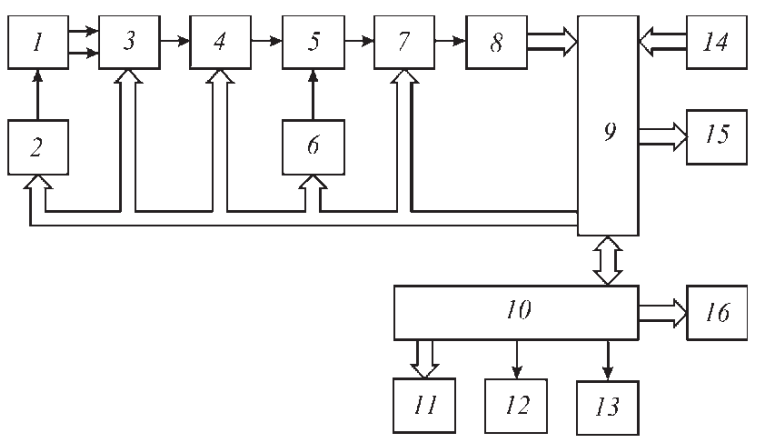

Fig. 5. Structural scheme of Eddycon VD 3-81 type flaw detector

Experimental investigations were carried out with the application of the conventional testing machine for tensile loading and the specially developed setup for four-point loading by pure bending scheme. Stress values were calculated with the application of the displacement indicator readout (scale division value, $0.01 \mathrm{~mm}$ ), which indicates the deformation of specimen in central point under the different level of applied force $P$. The indicator was calibrated in stress units preliminarily (before the investigations) by force dynamometer application. Tensile and compressive stresses were obtained on different sides of specimen due to four-point loading scheme application. It is important, that the diagram of bending moments $M$ and stresses in the center of specimen (between the points of the force application $P$ on Fig. 6) don't changed. Transverse forces $Q$ in this area also are equal to zero. In that way the EC probe signal responses are not influenced by the position of the probe within this area along the specimen. The influence of the specimen edge was eliminated by accurate probe positioning.

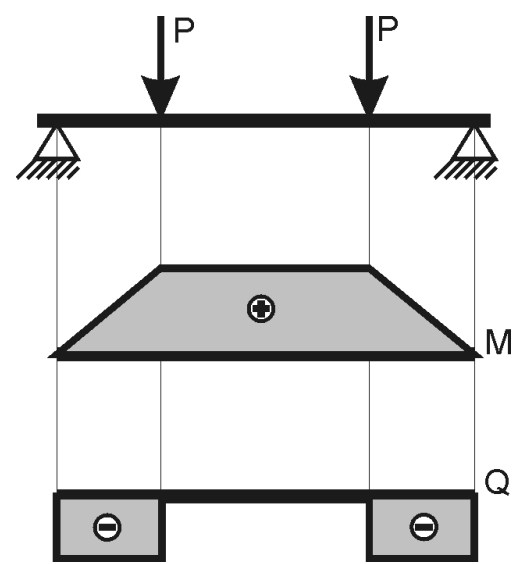

Fig. 6. Four-point loading scheme of pure bending and diagrams for the bending moments $M$ and transverse forces $Q$ 
Specimens for investigations were made from low carbon and middle carbon steels.

The specimen made of low-carbon steel (mass \%: $0.10 \mathrm{C}$; $0.42 \mathrm{Si} ; 1.47 \mathrm{Mn}$ ) was $450 \mathrm{~mm}$ long, $8 \mathrm{~mm}$ thick and $60 \mathrm{~mm}$ wide. This specimen was annealed before loading at $720{ }^{\circ} \mathrm{C}$ during $1 \mathrm{~h}$ (mainly ferrite structure with yield strength $\sigma_{Y S}=305 \mathrm{MPa}$ ) to remove the potential residual stresses and investigated using set-up for four-point bending (Fig. 6).

Two specimens made of middle-carbon steel (mass \%: $0.66 \mathrm{C}$; $0.29 \mathrm{Si} ; 1.02 \mathrm{Mn} ; 0.12 \mathrm{Cr}$ ) were $150 \mathrm{~mm}$ long, $3 \mathrm{~mm}$ thick and $30 \mathrm{~mm}$ wide. These specimens were used to investigate the influence of the steel microstructure on the EC probe signal response under the tensile loading. The first specimen was annealed at $830{ }^{\circ} \mathrm{C}$ during $2 \mathrm{~h}$ and contains mainly pearlite structure $\left(\sigma_{Y S}=560 \mathrm{MPa}\right)$. The second specimen was quenched (from $830^{\circ} \mathrm{C}$, cooling in oil) and tempered (at $380{ }^{\circ} \mathrm{C}$ during $2 \mathrm{~h}$ ) and contains mainly troostite structure $\left(\sigma_{Y S}=1510 \mathrm{MPa}\right)$.

During the experiments the EC probe was mounted in middle part of the specimen in the unloaded state (before the loading) by spring bracket to minimize the clearance between specimen surface and the EC probe to zero. After that, the EC probe signal response was balanced automatically by the proper procedure of vector summation, which is typical for modern EC flaw detector. Due this procedure the initial components of the material electrophysical properties anisotropy, concerned with material texture and specimen form, were eliminated. After the balancing, the original point of signal response in complex plane on the flaw detector display was located in the center (marked by number 1 in Fig. 7). Then the specimen was loaded to create the tensile or compressive stresses. Before the investigation, the direction of hodograph for tensile loading was oriented to go vertically up by usual for EC flaw detector operation of phase rotation. The signal response changes during the specimen loading and subsequent unloading were recorded in complex plane in the form of hodograph or the increments of the signal amplitude were registered.

\section{RESULTS AND DISCUSSION}

\subsection{The Influence of Tensile and Compressive Loading on the EC Probe Signal Response}

In this investigation the low-carbon steel specimen was loaded to create the tensile and compressive stresses from unloaded state up to $225 \mathrm{MPa}$. For this purpose the EC probe was mounted on different sided

of specimen loaded by four-point scheme. The EC probe signal response hodographs in complex plane obtained on operational frequencies $5 \mathrm{kHz}$ and $50 \mathrm{kHz}$ are presented in Fig. 7.

We can notice that hodographs for 5 and $50 \mathrm{kHz}$ are very similar. During the loading, the ends of the signal vector were moving from the initial zero point along the hodograph lines to points concerned with maximal signal amplitude. When the specimen was unloaded the ends of signal vector retained to initial zero point by the same trajectory.

a)

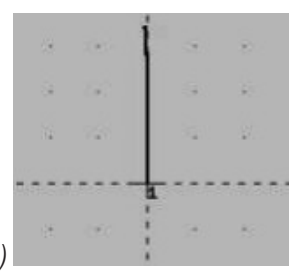

c)

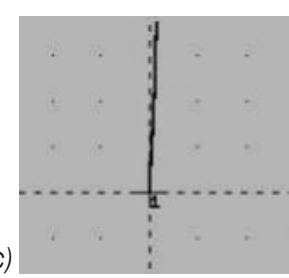

Fig. 7. Hodographs of EC probe signal responses in complex plane for a) and c) tensile and b) and d) compressive stresses on operational frequencies a) and b) 5.0 and c) and d) $50.0 \mathrm{kHz}$

One might notice that hodographs obtained for tensile and compressive stresses have opposite directions in the complex plane. This peculiarity enables the indication of stress type (tensile or compressive) if the balancing procedure was carried out on the specimen with really unloaded state. Results obtained show that the developed EC probe is sensitive to stresses even when high enough operational frequency $(50 \mathrm{kHz})$ was applied.

The dependences of EC probe signal amplitude $U_{\sigma}$ (in volts) on the tensile and compressive stresses $\sigma^{\circ}$ on the operational frequency $5.0 \mathrm{kHz}$ are presented in Figs. 8 and 9. The EC probe signal amplitudes were measured during loading trials up to $225 \mathrm{MPa}$ and subsequent unloading to fully-unloaded state.

Presented results demonstrate high sensitivity of the developed double differential type EC probe to tensile and compressive stresses and the magneticmechanical hysteresis existence. The nature of magnetic-mechanical hysteresis can be explained by the influence of mechanical hysteresis combined with the influence of magnetic hysteresis.

It is clear that observed hysteresis can produce the relevant errors during the stress measurements. 
Therefore, some methods to suppress concerned with the hysteresis errors were developed [14], [15] and [19]. On the other hand, the existence of such kind of errors is not essential for comparative inspection, when the stress distribution or the difference of the stresses on the specified points of the inspected surface is more informative, than the absolute value of stress.

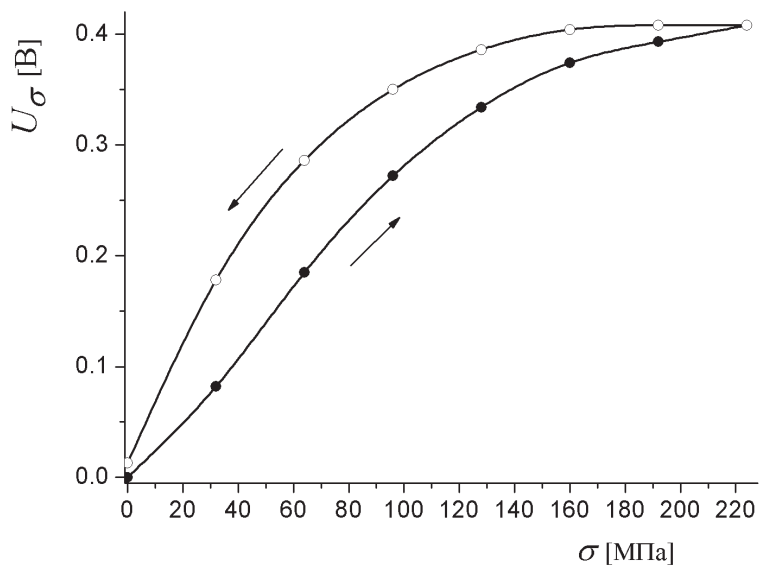

Fig. 8. Changes in EC probe signal amplitude during tensile loading $(\bullet)$ and subsequent unloading $(0)$

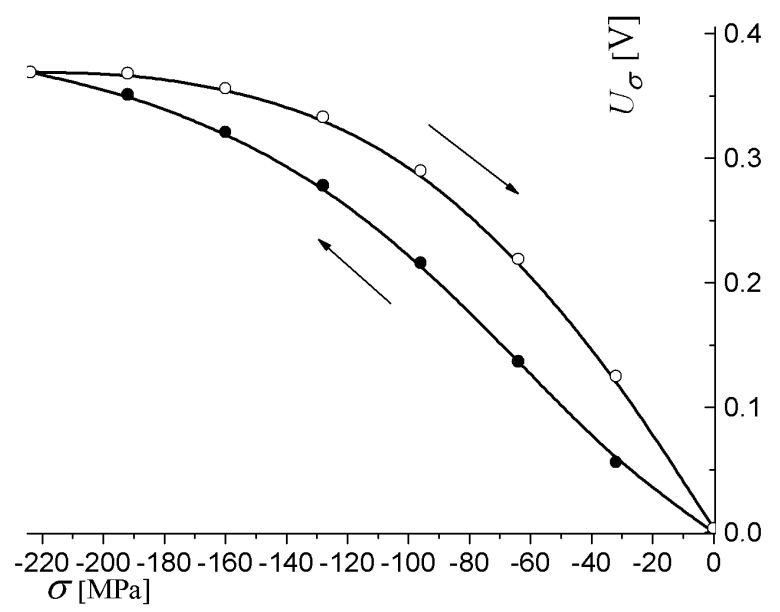

Fig. 9. Changes in EC probe signal amplitude during compressive loading $(\bullet)$ and subsequent unloading ( $(0)$

\subsection{Investigation of the Steel Microstructure Influence}

For next experiment two middle-carbon steel specimens were heat treated in different ways to obtain the different microstructure of steel. These specimens were loaded on the tensile machine up to $500 \mathrm{MPa}$. Stress-induced changes in EC probe signal response amplitude $U$ were evaluated (Fig. 10). Here only loading branches of relative characteristics were recorded.
We can notice that the experimental points for loading branch are located on the same graph for the different structural state of specimen material. So, these results demonstrate the invariant feature of MA method in relation to the structural state of the steel. In other words - MA method is insensitive to structural state of stressed steel. Certainly, next investigations are needed to check this preliminary conclusion for different structural states and grades of steel.

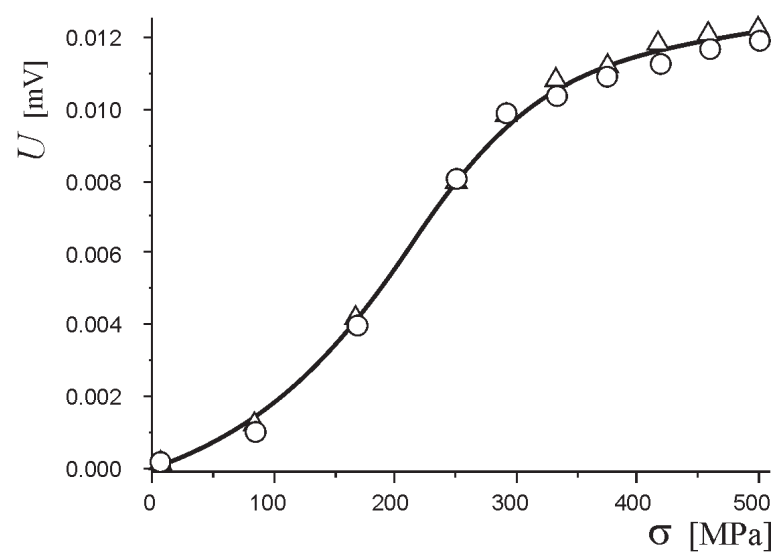

Fig. 10. Dependences of EC probe signal $U$ on tensile stress $\sigma$ in annealed $(\Delta)$ and quenched with tempering $(0)$ states

The last result can create the outlook for stress measurement independently of the structural state of material as opposed to other known magnetic methods based on coercivity or Barkhausen noise measurements.

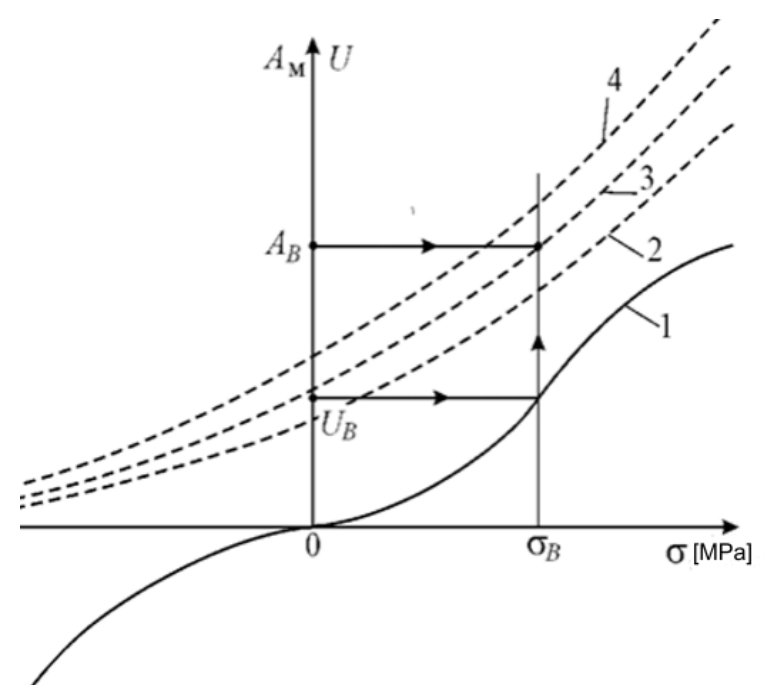

Fig. 11. Complex analysis of the Barhausen noise and MA sensitive EC probe signals for separable estimation of structural and stress state 
The idea of possible algorithm for separable structural and stress state determination based on the complex analysis of Barhausen noise technique (for example) and MA sensitive EC probe signals is shown in schematic generalized form in Fig. 11 [22]. The stress $\sigma_{M A}$ can be estimated from measured value of MA probe signal amplitude $U_{M A}$ using the dependence $U=f(\sigma)$ (curve 1). Then, from measured Barhausen parameter $A_{B}$ and known stress $\sigma_{M A}$ from the the dependences of Barhausen maximal amplitude $A$ on the stresses for different structural state (curves 2, 3 and 4) the relevant curve, which characterized the structural state of inspected material, can be determined (curve 3 in our example).

\section{APPLICATIONS}

Two original applications of the MA method for stress determination were proposed and realized. In these applications, the possibility of contactless measurements and simple removability of EC probe create new possibilities for nondestructive inspection.

\subsection{Determination of Residual Stressed in Welding}

EC method based on stress-induced MA changes can be applied for estimation of residual stresses in welding. Next result was obtained by experimental pipeline application $(168 \mathrm{~mm}$ in diameter and $22 \mathrm{~m}$ long with circular weld joints every $1000 \mathrm{~mm}$ ). The width of heat affected zone in welding was estimated about $70 \mathrm{~mm}$.

It was determined the distribution of stresses with distance $l$ (Fig. 12) in the direction perpendicular to welding line.

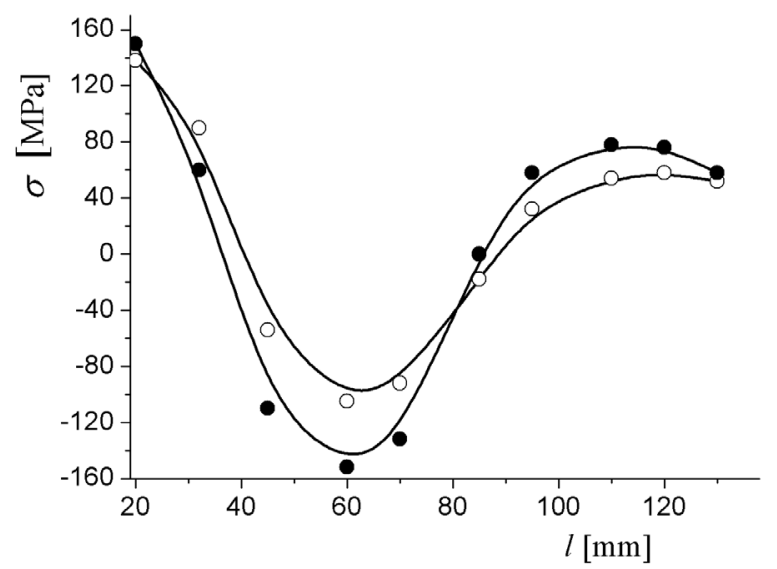

Fig. 12. Distribution of residual stresses in tube circular welding obtained by EC (०) and hole-drilling $(\bullet)$ methods
The EC MA meter was preliminary calibrated by four-loading set-up application (Fig. 6). The operational frequency is $700 \mathrm{~Hz}$. The depth of EC penetration is estimated about $0.8 \mathrm{~mm}$ to $0.9 \mathrm{~mm}$. The results obtained by EC method were compared with the traditional hall-drilling method. The drill diameter is $1.6 \mathrm{~mm}$. The depth of drilling is $0.8 \mathrm{~mm}$.

Presented results show the specific distribution of residual stresses in welding area [3].

\subsection{Determination of the Stresses in Bridge Framework Walls during the Launching to the Pillars}

Proposed MA technique of stress measurement was applied to estimate the balance between the different sidewalls during the bridge framework launching to the pillars to prevent possible disaster [23]. The proposed method was tested at the time of the launching the bridge framework during the building of the bridge across the Dnieper river in Kiev. The bridge framework has 2 box sections with dimensions 3240 $\mathrm{mm} \times 2360 \mathrm{~mm}$ and $12 \mathrm{~mm}$ wall thickness. For stress determination two EC probes were mounted on the extreme opposite framework walls in compressed area (200 $\mathrm{mm}$ from the framework edge) directly above the expansion pedestal area. After every framework displacement (about $1 \mathrm{~m}$ ) the console length of bridge framework $L$ was increased and the point of measurement was displaced also. The EC probes were oriented to estimate the horizontal compressive stresses, which have maximal value in the point above the expansion pedestal.

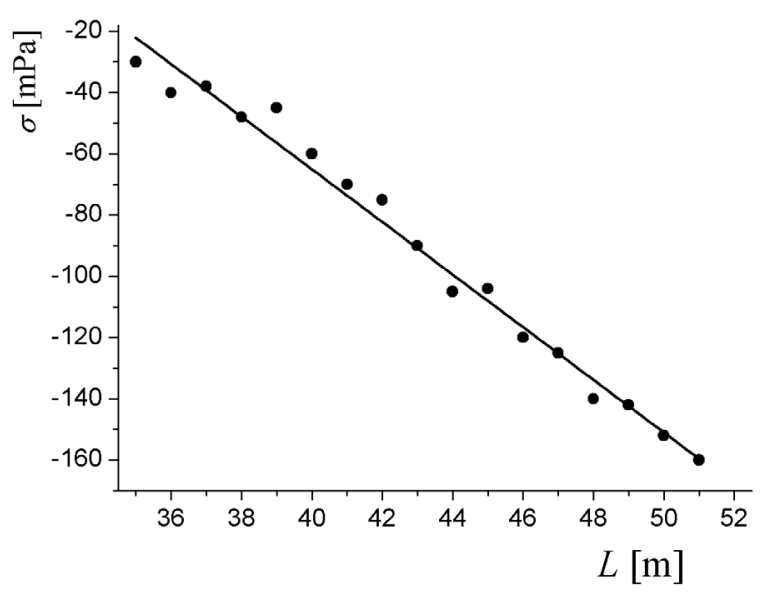

Fig. 13. The dependence of the measured stress $\sigma$ on the console length $L$

The dependence of measured stress $\sigma$ on the console length $L$ (Fig. 13) shows that the compressive stresses in the expansion pedestal area are increased 
linearly during the process of launching. The procedure of the measurement of stress changes in the bridge framework wall at the time of the launching is presented in Fig. 14.

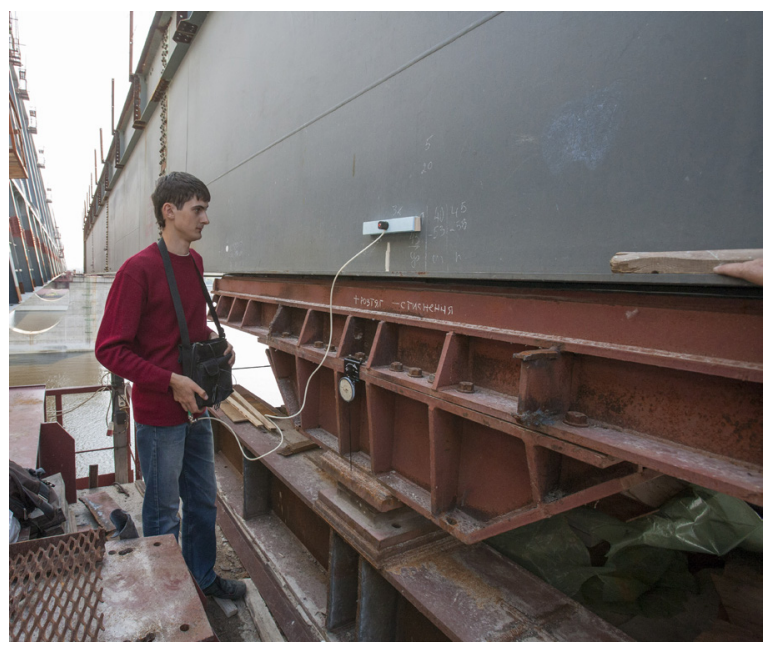

Fig. 14. The measurement of stress changes in the bridge framework sidewall at the time of the launching

Simple removability of EC probe during the launching process and the possibility of stress determination without the direct contact with the surface of the inspected component are the main advantages of EC method in comparison with the tensometric strain-gage testing. The monitoring of the changes of the stresses in framework walls during the launching process permits to prevent possible disaster.

\section{TASKS FOR FUTURE WORKS}

Future investigations and elaborations are concerned with next topics:

1. The investigation of the nature of the magnetomechanical hysteresis with the purpose to minimize the relevant errors;

2. To investigate and generalize the invariant property of MA method in relation to the structural state for different grade steels.

\section{CONCLUSIONS}

1. The hodographs of the signal responses of the developed EC probe in complex plane under the influence of tensile and compressive stresses in ferromagnetic steel were investigated. The opposite direction of hodographs for tensile and compressive stresses was shown. This peculiarity creates the possibility to determine the type of stress (tensile or compressive). The existence of the magneto-mechanical hysteresis even in the elastic loading range also was shown both for tensile and compressive loading.

2. The invariant property of magnetic anisotropy EC probe signal under the tensile stress influence in relation to the structural state of ferromagnetic steel was shown. The idea of stress and structural state of material estimation was shown.

3. Two practical applications of the MA method for stress determination were presented: the determination of the residual stresses in pipeline welding area and applied stresses in the bridge framework walls during the process of framework launching to the pillars.

\section{REFERENCES}

[1] De, A., DebRoy, T. (2011). A perspective on residual stresses in welding. Science and Technology of Welding and Joining, vol. 16, no. 3, p. 204-208, Dol:10.1179/13621711 $1 \times 12978476537783$.

[2] Nitschke-Pagel, T., Wohlfahrt, H. (2002). Residual stresses in welded joints - Sources and consequences. Material Science Forum, vol. 404-407, p. 215-226, D0l:10.4028/www.scientific. net/MSF.404-407.215.

[3] Withers, P.I., Turski, M., Edwards, L. Bouchard, P.J., Buttle, D.J. (2008). Resent advances in residual stress measurement. International Journal of Pressure Vessels and Piping, vol. 85, no. 3, p. 118-127, D0l:10.1016/j.ijpvp.2007.10.007.

[4] Vengrinovich, V., Tsukerman, V., Denkevich, Y., Bryantsev, D. (2006). The new parameters to characterize internal stresses via Brakhausen Noise. Proceedings of the 9th European Conference on NDT, p. 1-7.

[5] Yelbay, I.H., Cam, I., Gur, H. (2010). Non-destructive determination of residual stress state in steel weldment by magnetic Barkhausen noise technique. NDT \& E International, vol. 43, no. 1, p. 29-33, D0l:10.1016/j.ndteint.2009.08.003.

[6] Gur, H., Erlan, G., Batıgün, C., Çam, I. (2016). Investigating the effect of subsequent weld passes on surface residual stresses in steel weldments by magnetic Barkhausen noise technique. Materials Evaluation, vol. 74, no. 3, p. 408-423.

[7] Vourna, P., Ktena, A., Tsakiridis, P.E., Hristoforou, E. (2015). A novel approach of accurately evaluating residual stress and microstructure of welded electrical steels. NDT \& E International, vol. 71, p. 33-42, D0l:10.1016/j. ndteint.2014.09.011.

[8] Zerovnik, P., Grum, J. (2006). Comparative measurements of residual stresses with the method based on the magnetic Barkhausen noise and relaxation method. International Journal of Microstructure and Materials Properties, vol. 1, no. 3-4, p. 321-333, D0I:10.1504/IJMMP.2006.011647.

[9] Stuecker, E., Hofer, G., Koch, D., Guenes, U. (1989). Method and Apparatus for Measuring and Precisely Locating Internal Tensile Stresses in Hardened Regions of Components by Measuring Coercive Field Strength and Barkhausen Noise Amplitude, USA Patent no. 4881030. USPTO, Washington. 
[10] Langman, R.A., Mutton, P.J. (1993). Estimation of residual stresses in railway wheels by means of stress-induced magnetic anisotropy. NDT \& E International, vol. 26 , no. 4, p. 195-205, DOI:10.1016/0963-8695(93)90474-9.

[11] Liu, H.S., Yin, C.H., Zhang L., Mao, X.B., Miao, X.X., Lu, A.H. (2009). Improvement of magnetic residual stress measurements based on Fourier transform. Material Science and Technology, vol. 25, no. 6, p. 743-746, DOI:10.1179/174328408X322187.

[12] Kuo, S.-K., Lin, S.-Y., Lu, C.-Y. (2012). Characterization of magnetic field rotation of steel sheet under uniaxial stress. Measurement, vol. 45, no. 5, p. 1239-1245, D0l:10.1016/j. measurement.2012.01.013.

[13] Grigoryan, S.G. (2012). A method of determination of the components of tensor of mechanical stresses in products from ferromagnetic materials. Russian Electromechanics, no. 1, p. 28-33. (in Russian)

[14] Zhukov S.V., Zhukov V.S. (1997). Device for Measurement of Mechanical Stresses in Metal Product. Russian Patent no. 2079825, Russian Patent Office, Moscow. (in Russian)

[15] Zhukov, S.V., Zhukov, V.S., Kopytsa, N.N. (2002). Method for Determination of Mechanical Stresses and Device of Its Realization. Russian Patent no. 2195636, Russian Patent Office, Moscow. (in Russian)

[16] Fomichov, S., Minakov, S., Michalko, S., Yaremenko, M., Minakov, A. (2009). The determination of the force action on the pipeline by the longitudinal stresses distribution analyzing. Technical Diagnostics and Nondestructive Testing, no. 2, p. 11-14. (in Russian)
[17] Sakai Y., Unishi, H., Yahata, T. (2004). Non-destructive method of stress evaluation in linepipes using magnetic anisotropy sensor. JFE Technical Report, no. 3, p. 47-53.

[18] Liu, H., Dun, C., Dou, L., Yang, W. (2011). Theoretical analysis of magnetic sensor output voltage. Journal of Magnetism and Magnetic Materials, no. 323, no. 12, p. 1667-1670, D0I:10.1016/j.jmmm.2011.01.034.

[19] Kishimoto, S., Kobayashi M., Kodaira Y., Kobayashi, M., Yamada, H. (1990). Non-contact stress measurement of rail steel using a magnetic anisotropy sensor. IEEE Translation Journal on Magnetics in Japan, vol. 5, no. 9, p. 762-767, Dol:10.1109/TJMJ.1990.4564337.

[20] Uchanin, V. (2013). Surface Double Differential Type Eddy Current Probes. Spolom, Lviv. (in Ukrainian)

[21] Uchanin, V., Lutsenko, G., Opanasenko, A., Dzhaganian, A. (2016). PROMPRYLAD family of eddy current flaw detectors - from simple to more complicated. Proceedings of the $19^{\text {th }}$ World Conference on NDT, p. 1-8.

[22] Uchanin, V., Minakov, S., Ostash, O., Bezlyudko, G., Minakov, A. (2015). Method for Complex Electromagnetic Testing of Structural and Stress State of Ferromagnetic Materials, Ukrainian patent no. 100379, Ukrainian Intelectual Property Institute, Kyiv. (in Ukrainian)

[23] Uchanin, V., Minakov, S., Fomichov, S., Minakov, A., Bobin, B. (2017). Method of Framework Launching during the Bridge Building, Ukrainian Patent no. 116454, Ukrainian Intelectual Property Institute, Kyiv. (in Ukrainian) 